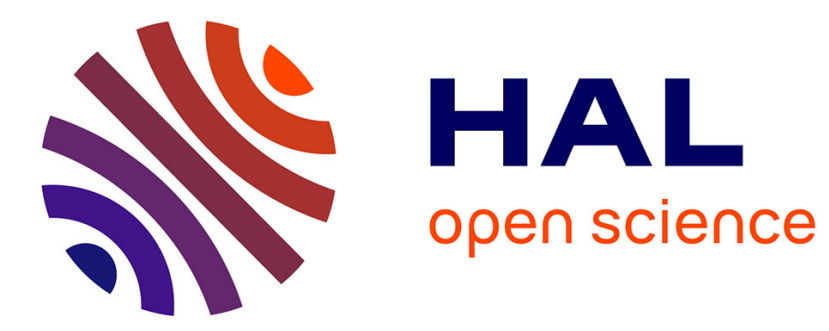

\title{
High-temperature hydrogen anneal of mnos structures
}

G. Schols, H. Maes, G. Declerck, R. van Overstraeten

\section{To cite this version:}

G. Schols, H. Maes, G. Declerck, R. van Overstraeten. High-temperature hydrogen anneal of mnos structures. Revue de Physique Appliquée, 1978, 13 (12), pp.825-828. 10.1051/rphysap:019780013012082500 . jpa-00244554

\section{HAL Id: jpa-00244554 https://hal.science/jpa-00244554}

Submitted on 1 Jan 1978

HAL is a multi-disciplinary open access archive for the deposit and dissemination of scientific research documents, whether they are published or not. The documents may come from teaching and research institutions in France or abroad, or from public or private research centers.
L'archive ouverte pluridisciplinaire HAL, est destinée au dépôt et à la diffusion de documents scientifiques de niveau recherche, publiés ou non, émanant des établissements d'enseignement et de recherche français ou étrangers, des laboratoires publics ou privés. 


\title{
NON VOLATILE MEMORY STRUCTURES.
}

\section{HIGH-TEMPERATURE HYDROGEN ANNEAL OF MNOS STRUCTURES}

\author{
G. SCHOLS, H. MAES $\left({ }^{*}\right)$, G. DECLERCK $\left({ }^{*}\right)$ and R. VAN OVERSTRAETEN
}

\author{
Katholieke Universiteit Leuven, Departement Elektrotechniek, ESAT, \\ Kardinaal Mercierlaan 94, B-3030 Heverlee, Belgium
}

\begin{abstract}
Résumé. - Cet article traite l'évolution de la densité d'états d'interface au cours de recuits à hautes températures en hydrogène par des fenêtres dans la couche de nitrure de silicium à proximité des régions MNOS actives. On observe une influence apparente de la géométrie des structures MNOS en conséquence du mécanisme de diffusion latérale de l'hydrogène. En dehors de cette diffusion latérale on observe également une diffusion verticale de l'hydrogène à travers la couche de nitrure à des températures au-delà de $850^{\circ} \mathrm{C}$.
\end{abstract}

\begin{abstract}
The effects on fast surface state density due to high-temperature hydrogen anneals through windows in the silicon nitride layer next to the active MNOS regions are presented. A marked geometry effect is observed as a result of the occurring lateral hydrogen diffusion mechanism. Besides this lateral diffusion process, a vertical hydrogen diffusion through the nitride layer is observed at temperatures above $850^{\circ} \mathrm{C}$.
\end{abstract}

1. Introduction. - It is well known that the density of fast surface states, located at the $\mathrm{SiO}_{2}$-Si interface of thermally oxidized silicon structures is reduced during the low-temperature $\left(400-500{ }^{\circ} \mathrm{C}\right)$ aluminum sintering step in nitrogen or forming gas $\left(10 \% \mathrm{H}_{2}, 90 \% \mathrm{~N}_{2}\right)$.

In order to test Balk's hypothesis [1] that some hydrogen form is responsible for the reduction of fast surface state density, Castro and Deal [2] annealed MOS structures in $100 \%$ hydrogen. They found that a low-temperature treatment $\left(400-500^{\circ} \mathrm{C}\right)$ in a hydrogen ambient is almost as effective in reducing the density of fast surface states as the aluminum sintering step.

In the case of MNOS structures, however, it has been reported by Deal, MacKenna and Castro [3] that the very dense structure of the silicon nitride layer prevents or at least retards the diffusion of hydrogen through the nitride layer during the aluminum sintering step, so that little or no reduction of fast surface state density is observed.

However, if the silicon nitride is removed in the vicinity of the active MNOS regions, it is possible to reduce the number of fast surface states by means of a heat treatment in $100 \%$ hydrogen. In that case, the hydrogen diffuses vertically through the windows in the nitride layer and migrates then horizontally into the active MNOS regions to the $\mathrm{SiO}_{2}-\mathrm{Si}$ interface, where it annihilates the fast surface states.

In the case of MOS structures the hydrogen has only to diffuse through an oxide thickness of 1000 to $2000 \AA$ to reach the $\mathrm{SiO}_{2}-\mathrm{Si}$ interface. For MNOS structures, where the hydrogen has to diffuse from outside the active regions, through the cutouts in the silicon nitride layer, the diffusion length, in order to reach the $\mathrm{SiO}_{2}-\mathrm{Si}$ interface at the center of the structure, is considerably larger, typically 100 to

$\left(^{*}\right)$ Fellow (bevoegd verklaard navorser) NFWO.
1000 times larger. Therefore, if, in the case of MNOS structures, the anneal temperature is increased, not only will the available amount of active hydrogen in the annealing ambient be larger, but also will the diffusion coefficient of the hydrogen increase, so that the lateral hydrogen diffusion into the active MNOS regions will be accelerated.

A program is carried out to study the influence of high-temperature hydrogen anneal on the number of fast surface states at the $\mathrm{SiO}_{2}-\mathrm{Si}$ interface. The results of these experiments are summarized in this paper.

2. Experimental. - 2.1 Processing. - All silicon used as starting material for this work is n-type with a concentration of $1.1 \times 10^{15} \mathrm{~cm}^{-3}$. Crystal orientation is $(100)$.

The different technological steps involved are presented in figure 1. After a standard cleaning procedure the wafers are thermally oxidized to give an oxide thickness of approximately $1 \mu \mathrm{m}$ (Fig. 1a). Using conventional photoresist and etching techniques, the active MNOS regions are defined (Fig. 1b). A thin oxide is then thermally grown in dry oxygen for $30 \mathrm{~min}$., at $780^{\circ} \mathrm{C}$, followed by a silicon nitride deposition for $7 \mathrm{~min}$. at $800^{\circ} \mathrm{C}$ using the silaneammonia reaction (Fig. 1c). The ellipsometrically measured thicknesses of the thin oxide and the silicon nitride layers are respectively $50 \AA$ and $770 \AA$.

The silicon nitride is removed next to the active regions (Fig. 1d). In a subsequent heat treatment in $100 \% \mathrm{H}_{2}$, the hydrogen diffuses vertically through these cutouts and migrates then horizontally into the active regions where it annihilates the fast surface states. Cooling after annealing is also in hydrogen, in order to prevent the out-diffusion of hydrogen and/or the introduction of new fast surface states when cooling in nitrogen. 


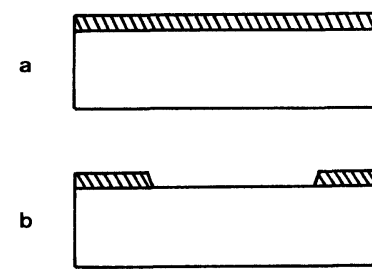

wafer cleaning

field oxide growth

active region definition

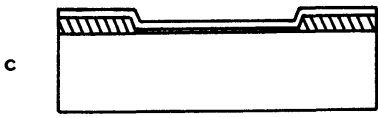

thin oxide growth

silicon nitride deposition

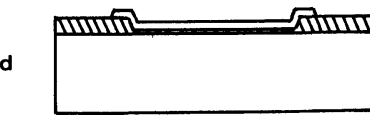

silicon nitride etching

hydrogen anneal

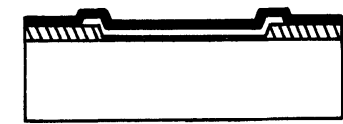

aluminum evaporation

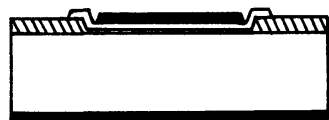

aluminum etching

back side Al-evaporation

aluminum sintering

FIG. 1. - Preparation of hydrogen-annealed MNOS structures.

Filament evaporation of the aluminum (Fig. 1e) is employed to avoid radiation-induced traps in the oxide, which are characteristic of electron-beam evaporation. After the metallization pattern definition (Fig. $1 f$ ), aluminum is also evaporated on the back side to ensure a good ohmic contact.

The final low-temperature sintering step is carried out at $450^{\circ} \mathrm{C}$ for $30 \mathrm{~min}$ in forming gas.

2.2 Evaluation. - The fast surface state density $N_{\text {ss }}$ is measured using the quasistatic low-frequency $\mathrm{C}-\mathrm{V}$ technique of Kuhn [4] and Castagné [5]. The current response of the MNOS capacitor on a linear voltage ramp is measured with an operational amplifier to plot the C-V curve directly. With this method it is very difficult to determine the density $N_{\text {ss }}$ with an accuracy better that $1.0 \times 10^{10} \mathrm{~cm}^{-2} \mathrm{eV}^{-1}$.

3. Results. - In order to find out for which temperature and time the hydrogen anneal is most effective in reducing the fast surface state density, different MNOS structures are processed which have the same history prior to and after the high-temperature hydrogen anneal. Only the anneal conditions are different.

As a reference for the measurements on the annealed structures, a $N_{\mathrm{ss}}$-value of $3.1 \times 10^{11} \mathrm{~cm}^{-2} \mathrm{eV}^{-1}$ is used, which is measured on not-annealed MNOS structures with an otherwise completely identical processing history as the annealed samples.

3.1 AnNeal temperature efFects. - The effect of anneal temperature in the $750-1050^{\circ} \mathrm{C}$ range on the fast surface state density is shown in figure 2 for MNOS structures with $300 \mu \mathrm{m}$ square dimensions. The anneal time is $60 \mathrm{~min}$. A decrease of $N_{\text {ss }}$ with increasing temperatures is observed [6]. A minimum $N_{\text {ss }}$-value is found at $1000^{\circ} \mathrm{C}$. For temperatures higher than $1050^{\circ} \mathrm{C}$ etching of the nitride layer takes place during the hydrogen anneal.

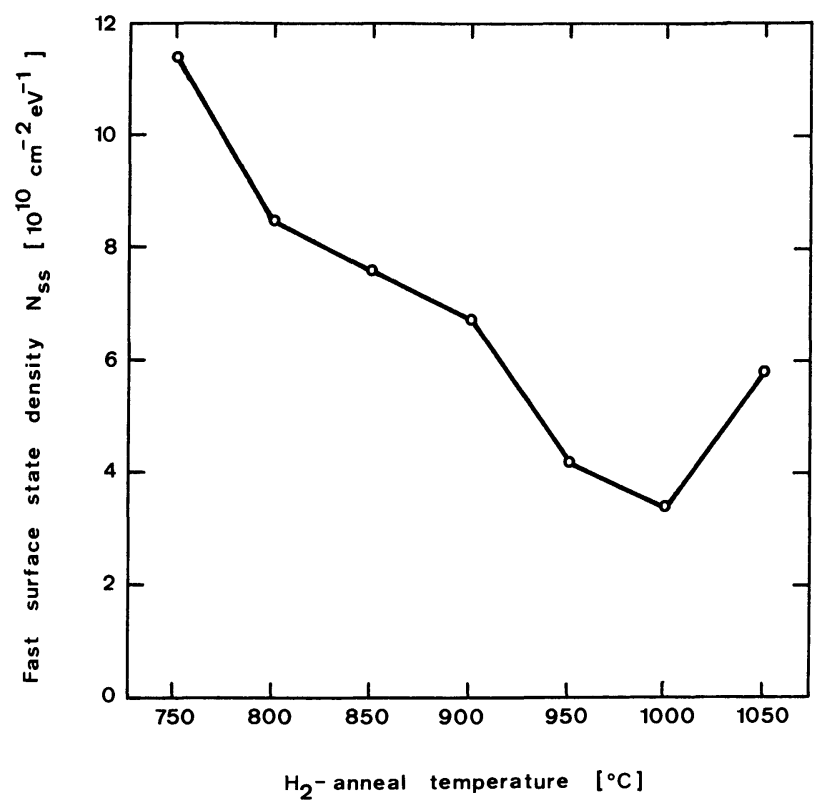

FIG. 2. - Anneal temperature dependence of fast surface state density $N_{\text {ss }}$ for hydrogen anneals of $300 \mu \mathrm{m}$ square MNOS structures. Anneal time is $60 \mathrm{~min}$.

3.2 AnNeal time EFFeCts. - The results of hydrogen anneals at $950^{\circ} \mathrm{C}$ for different anneal times on the same $300 \mu \mathrm{m}$ square MNOS structures are shown in figure 3. A decrease of $N_{\text {ss }}$ with increasing anneal

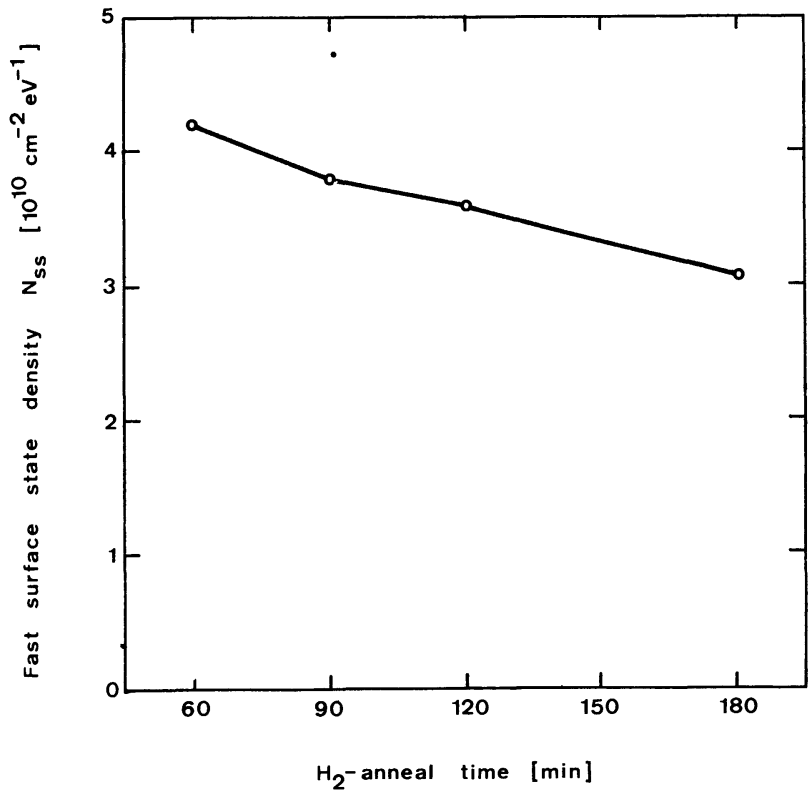

' FIG. 3. - Anneal time dependence of fast surface state density $N_{\text {Ss }}$ for hydrogen anneals of $300 \mu \mathrm{m}$ square MNOS structures. Anneal temperature is $950^{\circ} \mathrm{C}$. 
time is observed [6]. From the data in figures 2 and 3 it is obvious that a longer anneal at a lower temperature can be as effective as or even more effective than an anneal at a higher temperature. This can be useful in some cases, for instance, where we want to preserve some critical impurity diffusion profiles.

3. 3 Geometry efFeCts. - Figure 4 shows the effect of a hydrogen anneal at $900^{\circ} \mathrm{C}$ for $60 \mathrm{~min}$. on square MNOS structures with different dimensions. A marked geometry effect is observed. The smaller the structure dimensions, the lower will be the corresponding $N_{\mathrm{ss}}$-value and this for any anneal condition (temperature and time). In other words, the described high-temperature hydrogen anneal is indeed characterized by a lateral diffusion process. In the case of smaller structures, the hydrogen, passing through the cutouts in the nitride layer, has to diffuse over shorter distances under the nitride gate in order to reach the center of the active MNOS region, than in the case of the larger structures. The technique is therefore more suitable in reducing the density of fast surface states under gates with relatively small dimensions.

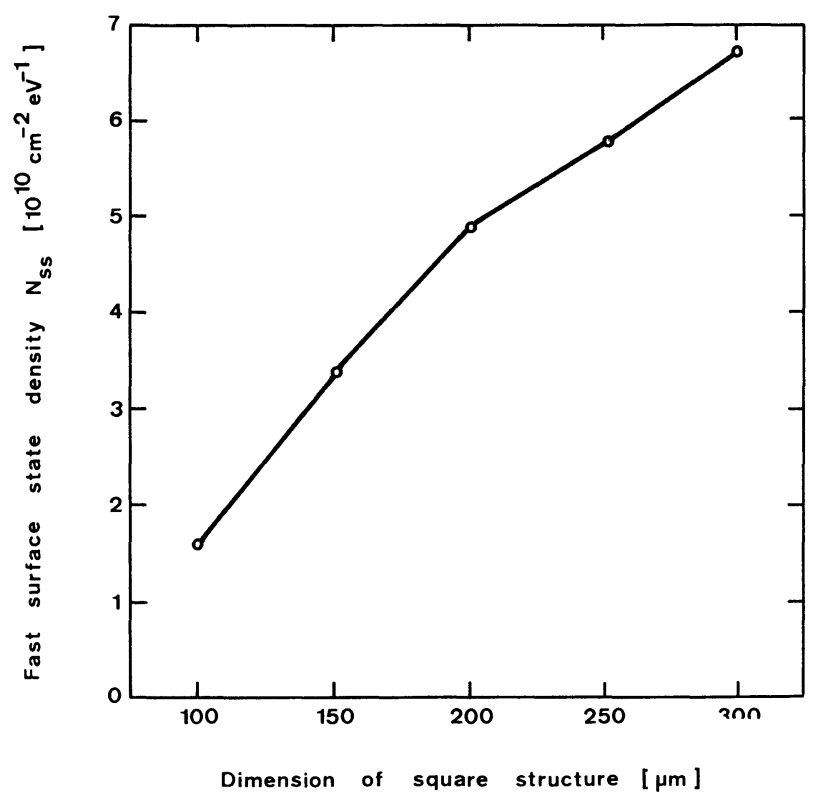

FIG. 4. - Dependence of fast surface state density $N_{\mathrm{ss}}$ on the dimension of square MNOS structures for hydrogen anneals at $900{ }^{\circ} \mathrm{C}$ for $60 \mathrm{~min}$.

The smallest dimension of the structure determines the effectiveness of the hydrogen anneal. This is obvious when we compare figure 4 with figure 5 , which shows the effect of a hydrogen anneal under the same conditions as in figure $4\left(900^{\circ} \mathrm{C}, 60 \mathrm{~min}\right)$ on MNOS structures with a smallest dimension of $100 \mu \mathrm{m}$ and with the other dimension varying between $100 \mu \mathrm{m}$ and $1000 \mu \mathrm{m}$.

3.4 LATERAL DIFFUSION EFFECTS. - As a result of the lateral hydrogen diffusion, the anneal is found to

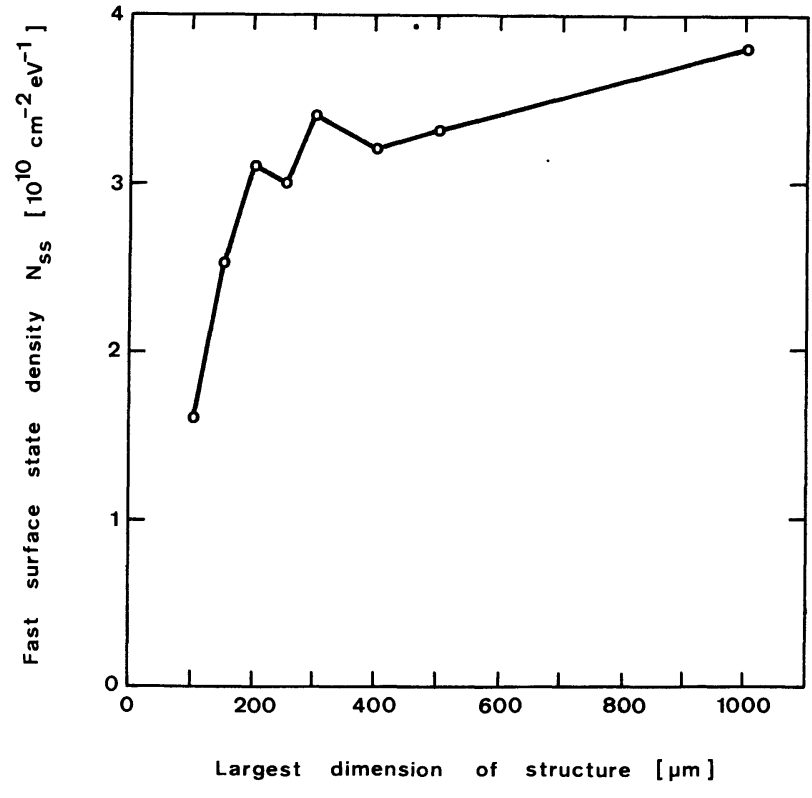

Fig. 5. - Dependence of fast surface state density $N_{\text {Ss }}$ on the largest dimension of MNOS structures with a smallest dimension of $100 \mu \mathrm{m}$. Hydrogen anneal conditions are $900^{\circ} \mathrm{C}$ and $60 \mathrm{~min}$.

be incomplete for structures with relatively large dimensions, resulting in a non-uniform $N_{\mathrm{ss}}$ profile under the nitride gate. Only the edge region of the structure is completely annealed, showing a $N_{\mathrm{ss}}$-value lower than $10^{10} \mathrm{~cm}^{-2} \mathrm{eV}^{-1}$ (Fig. 6). With a specially designed device the width $\mathrm{w}$ of this edge region is determined to be $85 \mu \mathrm{m}$ after an anneal at $950^{\circ} \mathrm{C}$ for $60 \mathrm{~min}$. This means that MNOS structures with a smallest dimension of $170 \mu \mathrm{m}$ are completely annealed at $950{ }^{\circ} \mathrm{C}$, resulting in a $N_{\mathrm{ss}^{-}}$-value lower than $10^{10} \mathrm{~cm}^{-2} \mathrm{eV}^{-1}$ over the total structure area.

For smaller dimensions, for instance in the case of MNOS transistors, where the $\mathrm{H}_{2}$-anneal can be performed through the contact holes, lower anneal temperatures $\left(\leqslant 800^{\circ} \mathrm{C}\right)$ and/or shorter anneal times $\left(15 \mathrm{~min}\right.$.) will suffice to reduce $N_{\mathrm{ss}}$ below $10^{10} \mathrm{~cm}^{-2} \mathrm{eV}^{-1}$ under the transistor gate. Indeed, the distance between a contact hole and the center of the channel region is typically $15 \mu \mathrm{m}$, which is very much smaller than the $85 \mu \mathrm{m}$, previously mentioned. This result is important since a lower temperature range is

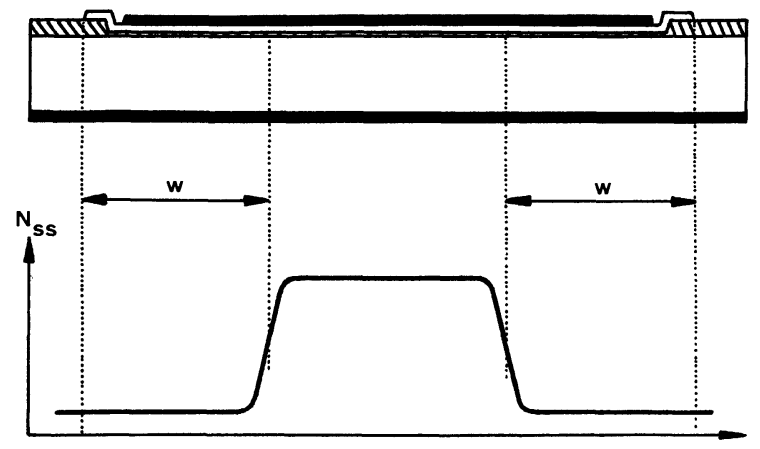

Fig. 6. - Non-uniform $N_{\text {ss }}$-profile as a result of the lateral hydrogen diffusion mechanism. 
also needed in order to preserve good quality of the silicon nitride layer in view of its memory retention capability [7].

3.5 VerTiCAL DIfFUSION EFFECTS. - For the MNOS structure of figure $7, N_{\mathrm{Ss}}$-measurements on the inner $100 \mu \mathrm{m}$ square aluminum gate $\mathrm{G}$, after $\mathrm{H}_{2}$-anneals of $60 \mathrm{~min}$. at different temperatures in the $900-1050^{\circ} \mathrm{C}$ range, give the path of figure 8 . Although this inner gate lays far enough from the nitride gate edge, so that lateral diffusion effects can be ignored, a reduction of the density of fast surface states is observed under this inner gate. This means that hydrogen has the possibility to diffuse through the nitride layer. This vertical diffusion mechanism depends strongly on the silicon nitride density. The result is a uniform reduction of $N_{\text {ss }}$ over the total MNOS device area, but it is hard to go below $10^{10} \mathrm{~cm}^{-2} \mathrm{eV}^{-1}$ for $N_{\mathrm{ss}}$, as is the case with the lateral diffusion mechanism.

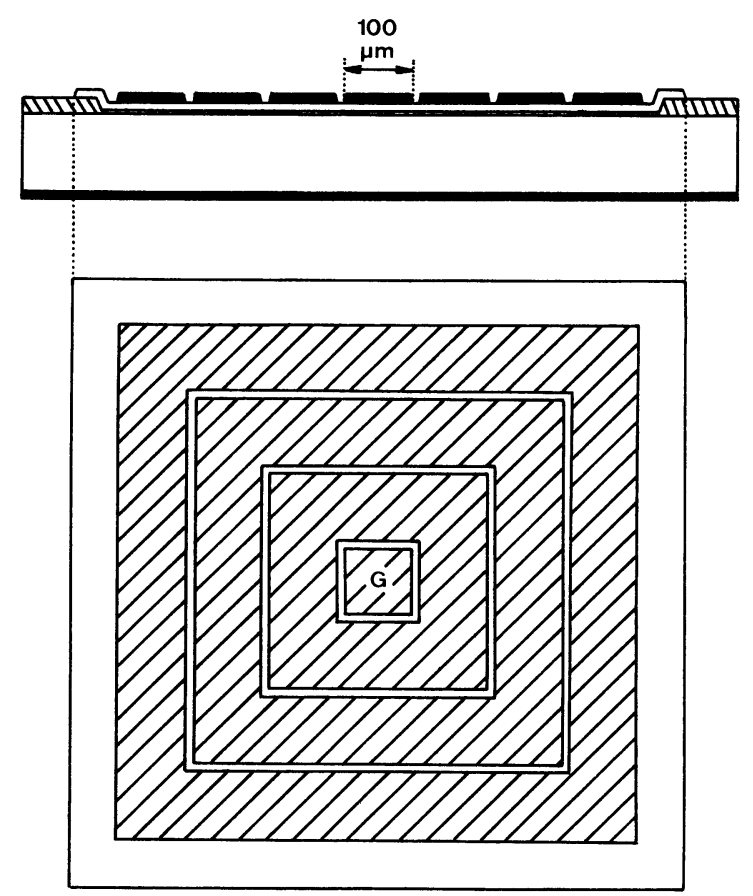

FIG. 7. - Large MNOS structure with ring-shaped aluminum gates for illustration of the vertical hydrogen diffusion mechanism through the nitride layer.

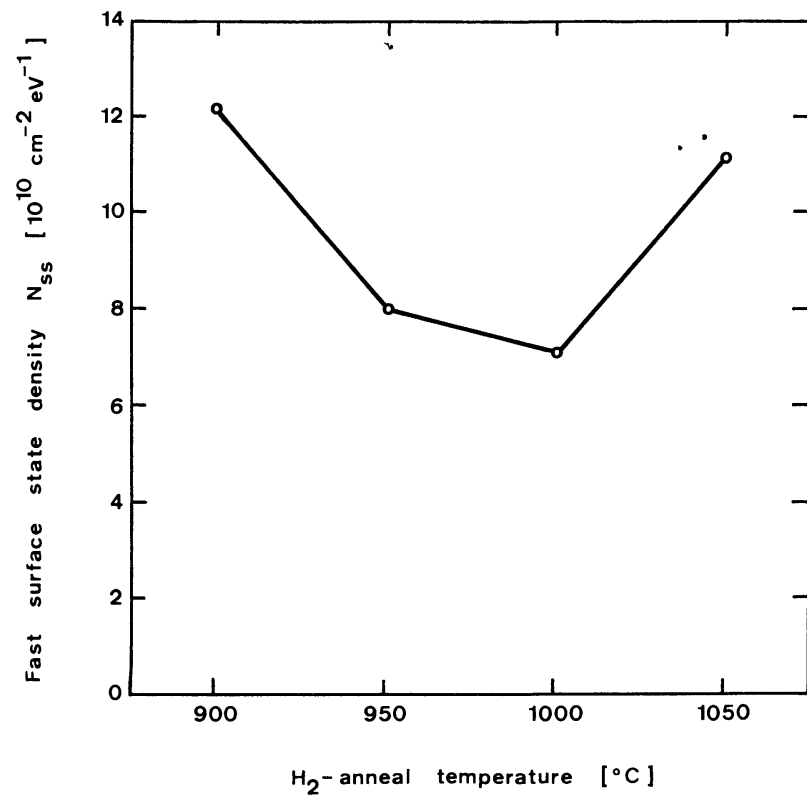

Fig. 8. - Anneal temperature dependence of fast surface state density $N_{\text {ss }}$ under the G-gates of the MNOS structures of figure 7 Anneal time is $60 \mathrm{~min}$.

4. Summary. - In order to reduce the density of fast surface states in MNOS structures by means of a high-temperature hydrogen anneal, the silicon nitride next to the active MNOS regions is removed, so that the hydrogen can penetrate into the active regions from where it migrates to the $\mathrm{SiO}_{2}-\mathrm{Si}$ interface, where it annihilates the fast surface states.

Summarizing, the results indicate that :

1) A maximum reduction of $N_{\mathrm{Ss}}$ after a 1 hour anneal occurs at $1000^{\circ} \mathrm{C}$, but a longer anneal at a lower temperature can be as effective as or even more effective than an anneal at a higher temperature.

2) A marked geometry effect is observed as a result of this lateral hydrogen diffusion mechanism.

3) Structures with a smallest dimension of $170 \mu \mathrm{m}$ can be completely annealed at $950^{\circ} \mathrm{C}$.

4) Besides this lateral diffusion process, a vertical diffusion through the nitride layer is observed at temperatures above $850^{\circ} \mathrm{C}$.

\section{References}

[1] BaLK, P., Paper 111 presented at the Buffalo Meeting of the Electrochemical Society, Oct. 10-14 (1965).

[2] Castro, P. L. and Deal, B. E., J. Electrochem. Soc. 118 (1971) 280.

[3] Deal, B. E., MacKenna, E. L. and Castro, P. L., J. Electrochem. Soc. 116 (1969) 997.

[4] KuнN, M., Solid-State Electron. 13 (1970) 873.
[5] Castagne, R. and Vapaille, A., Surf. Sci. 28 (1971) 157.

[6] Schols, G., Van Overstraeten, R. and Declerck, G. J., Paper 122 presented at the Washington Meeting of the Electrochemical Society, May 2-7 (1976).

[7] Topich, J. A. and Yon, E. T., J. Electrochem. Soc. 123 (1976) 539. 